\title{
Different Heart Rate Patterns During Cardio-Pulmonary Exercise (CPX) Testing in Individuals With Type 1 Diabetes
}

\author{
Othmar Moser ${ }^{1,2,3,4 *}$, Gerhard Tschakert ${ }^{1}$, Alexander Mueller ${ }^{1,5}$, Werner Groeschl ${ }^{1}$, \\ Max L. Eckstein ${ }^{3,4}$, Gerd Koehler ${ }^{2}$, Richard M. Bracken ${ }^{3,4}$, Thomas R. Pieber ${ }^{2}$ and \\ Peter Hofmann ${ }^{1}$ \\ ${ }^{1}$ Exercise Physiology, Training Therapy \& Training Research Group, Institute of Sports Sciences, University of Graz, Graz, \\ Austria, ${ }^{2}$ Division of Diabetology \& Metabolism, Department of Internal Medicine, Medical University of Graz, Graz, Austria, \\ ${ }^{3}$ Diabetes Research Group, School of Medicine, Swansea University, Swansea, United Kingdom, ${ }^{4}$ Applied Sport, \\ Technology, Exercise and Medicine Research Centre (A-STEM), College of Engineering, Swansea University, Swansea, \\ United Kingdom, ${ }^{5}$ Sports Science Laboratory, Institute of Health and Tourism Management, FH JOANNEUM-University of \\ Applied Sciences, Bad Gleichenberg, Austria
}

OPEN ACCESS

Edited by:

Michael Charles Riddell, York University, Canada

Reviewed by: Jennifer Kirby

University of Virginia, United States Jane Yardley,

University of Alberta, Canada

*Correspondence: Othmar Moser othmar.moser@swansea.ac.uk

Specialty section: This article was submitted to

Diabetes,

a section of the journal Frontiers in Endocrinology

Received: 29 April 2018 Accepted: 14 September 2018 Published: 02 October 2018

Citation:

Moser O, Tschakert G, Mueller A, Groeschl W, Eckstein ML, Koehler G,

Bracken RM, Pieber TR and Hofmann P (2018) Different Heart Rate Patterns During Cardio-Pulmonary Exercise (CPX) Testing in Individuals With Type 1 Diabetes. Front. Endocrinol. 9:585. doi: 10.3389/fendo.2018.00585
To investigate the heart rate during cardio-pulmonary exercise (CPX) testing in individuals with type 1 diabetes (T1D) compared to healthy (CON) individuals. Fourteen people (seven individuals with T1D and seven CON individuals) performed a CPX test until volitional exhaustion to determine the first and second lactate turn points $\left(\mathrm{LTP}_{1}\right.$ and LTP 2$)$, ventilatory thresholds $\left(\mathrm{VT}_{1}\right.$ and $\left.\mathrm{VT}_{2}\right)$, and the heart rate turn point. For these thresholds cardio-respiratory variables and percentages of maximum heart rate, heart rate reserve, maximum oxygen uptake and oxygen uptake reserve, and maximum power output were compared between groups. Additionally, the degree and direction of the deflection of the heart rate to performance curve ( $\left.k_{H R}\right)$ were compared between groups. Individuals with T1D had similar heart rate at LTP 1 (mean difference) -11 , [(95\% confidence interval) -27 to $4 \mathrm{~b} \cdot \mathrm{min}^{-1}$ ], at $\mathrm{VT}_{1}\left(-12,-8\right.$ to $\left.33 \mathrm{~b} \cdot \mathrm{min}^{-1}\right)$ and at $\operatorname{LTP}_{2}\left(-7,-13\right.$ to $\left.26 \mathrm{~b} \cdot \mathrm{min}^{-1}\right)$, at $\mathrm{VT}_{2}\left(-7,-13\right.$ to $\left.28 \mathrm{~b} \cdot \mathrm{min}^{-1}\right)$, and at the heart rate turn point $\left(-5,-14\right.$ to $\left.24 \mathrm{~b} \cdot \mathrm{min}^{-1}\right)$ $(p=0.22)$. Heart rate expressed as percentage of maximum heart rate at $\mathrm{LTP}_{1}, \mathrm{VT}_{1}$, $\mathrm{LTP}_{2}, \mathrm{VT}_{2}$ and the heart rate turn point as well as expressed as percentages of heart rate reserve at $\mathrm{LTP}_{2}, \mathrm{VT}_{2}$ and the heart rate turn point was lower in individuals with $\mathrm{T} 1 \mathrm{D}$ $(p<0.05)$. $\mathrm{k}_{\mathrm{HR}}$ was lower in T1D compared to CON individuals $(0.11 \pm 0.25$ vs. $0.51 \pm$ $0.32, p=0.02)$. Our findings demonstrate that there are clear differences in the heart rate response during $\mathrm{CPX}$ testing in individuals with T1D compared to CON individuals. We suggest using submaximal markers to prescribe exercise intensity in people with T1D, as the heart rate at thresholds is influenced by kHR.

\section{Clinical Trial Identifier: NCT02075567 (https://clinicaltrials.gov/ct2/show/ NCT02075567).}

Keywords: exercise prescription, heart rate to performance curve, thresholds, type 1 diabetes, heart rate reserve 


\section{INTRODUCTION}

Low amounts of structured exercise such as $3 \times 30 \mathrm{~min}$ per week are associated with consistent improvements in health status in already healthy and physically active individuals (1). In people with both type 1 (T1D) and type 2 diabetes high doses of physical activity were found to be associated with a $40 \%$ and $29 \%$ lower risk of all-cause mortality and cardiovascular disease in comparison with inactivity (2).

Currently, standard exercise recommendations for individuals with T1D are similar to those for healthy individuals, namely $150 \mathrm{~min}$ or more of moderate to intense exercise and physical activity spread over at least three days per week, or a minimum of $75 \mathrm{~min}$ per week of vigorous-intensity exercise/physical activity $(3,4)$.

Intriguingly, the American Diabetes Association (ADA) recommends prescribing exercise intensity as percentages of maximum heart rate (5) even though there is an ongoing debate on how to prescribe exercise intensity $(6,7)$. It was shown that the variable time course of the heart rate to performance curve influences exercise prescription, translating to uncertainty to overestimate target training loads especially in the vigorousintensity domain (8-11). Using percentages of maximum heart rate might be problematic as degree and direction of the deflection of the heart rate to performance curve $\left(\mathrm{k}_{\mathrm{HR}}\right)$ during CPX testing are altered in some healthy individuals (12) and might be further impaired by autonomic cardiac neuropathy in T1D individuals (13).

Furthermore, in T1D individuals with autonomic cardiac neuropathy, left ventricular function was found to be decreased in both systole and diastole, non-dipping was more prevalent, and pulse pressure was higher compared to patients without autonomic cardiac neuropathy (14). The heart rate to performance curve was shown to be related to myocardial function $(15,16)$. An increase in heart rate during CPX testing reflects the ability of the autonomic nervous system to respond to an increase in metabolic demands. In healthy individuals the increase in heart rate during CPX testing is mainly originated by a withdrawal of tonic vagal activity (17). As shown recently, individuals with T1D reveal a higher risk of impaired tonic vagal activity in comparison to their healthy counterparts (18). This impaired response of the autonomic nervous system might alter heart rate to performance curve, as found in our cohort.

\footnotetext{
Abbreviations: T1D, Type 1 diabetes/individuals with Type 1 diabetes; $\mathrm{HbA}_{1 \mathrm{c}}$, Glycated hemoglobin; BMI, Body mass index; ADA, American Diabetes Association; \% $\mathrm{HR}_{\max }$, Percentages of maximum heart rate; $\mathrm{HR}$, Heart rate; $\mathrm{k}_{\mathrm{HR}}$, Degree and direction of the deflection of the heart rate to performance curve; CPX, Cardio-pulmonary exercise testing; CON, Healthy individuals; \%HRR, Percentages of heart rate reserve; $\% \mathrm{VO}_{2 \max }$, Percentages of maximum oxygen uptake; $\% \mathrm{VO}_{2} \mathrm{R}$, Percentages of oxygen uptake reserve; $\% \mathrm{P}_{\max }$, Percentages of maximum power output; GCP, Good clinical practice; DoH, Declaration of Helsinki; MDII, Multiple daily insulin injections; CRF, Case Report Form; $\mathrm{P}_{\max }$, Maximum power output; $\mathrm{LTP}_{1}$, First lactate turn point; $\mathrm{LTP}_{2}$, Second lactate turn point; $\mathrm{VT}_{1}$, First ventilatory threshold; $\mathrm{VT}_{2}$, Second ventilatory threshold; VE, Ventilation; $\mathrm{VE} / \mathrm{VO}_{2}$, Ventilation of oxygen; $\mathrm{VE} / \mathrm{VCO}_{2}$, Ventilation of carbon dioxide; HRTP, Heart rate turn point; MD, Mean difference; CI, confidence interval.
}

As shown previously, different threshold concepts are suitable for healthy $(6,19)$ and T1D individuals $(20,21)$. The first threshold occurring during cardio-pulmonary exercise (CPX) testing [e.g., first lactate turn point $\left(\mathrm{LTP}_{1}\right)$ or the first ventilatory threshold $\left.\left(\mathrm{VT}_{1}\right)\right]$ translates to the inability of the muscle to entirely oxidize produced lactate and therefore it is partly shifted into the blood stream and can be metabolized by other organs. At this first threshold there is still a metabolically balanced condition but on a systemic level (22). At the second threshold [e.g., second lactate turn point $\left(\mathrm{LTP}_{2}\right)$ or the second ventilatory threshold $\left(\mathrm{VT}_{2}\right)$ ] produced lactate in the working muscles cannot be muscularly or systemically eliminated, resulting in a blood lactate accumulation (metabolically unbalanced condition, no lactate steady state) (6).

The aim of the study was to investigate the time course of the heart rate to performance curve during CPX testing in T1D individuals compared to matched healthy individuals (CON), and to prove its influence on percentages of maximum heart rate, percentages heart rate reserve, percentages maximum oxygen uptake, percentages oxygen uptake reserve and percentages maximum power output compared to standard markers of submaximal performance between groups. We determined as a primary outcome the heart rate to performance curve during CPX testing and its impact on target training heart rate determination in comparison of T1D individuals and matched healthy individuals (CON) and as secondary outcomes the functional capacity, cardiorespiratory and metabolic markers in comparison of groups during CPX testing. We hypothesized that people with T1D show an altered heart rate to performance curve during CPX testing and this impacts target training heart rate determination.

\section{METHODS}

\section{Consent Procedures}

This study was carried out in accordance with the recommendations of Good Clinical Practice (GCP), "Bundesamt fuer Sicherheit im Gesundheitswesen" (BASG Austria). The protocol was approved by the ethics committee of the Medical University of Graz, AT (26-069 ex 13/14). All subjects gave written informed consent in accordance with the Declaration of Helsinki. CON individuals were matched from routine diagnostics (approved by the Ministry of Science).

\section{Eligibility Criteria and Assessment}

To be eligible for the study, T1D individuals had to be male, diagnosed with T1D for at least 12 months, aged between 18 and 35 years (both inclusive), glycated hemoglobin $\left(\mathrm{HbA}_{1 \mathrm{c}}\right) \leq$ $8 \%\left(64 \mathrm{mmol} \cdot \mathrm{mol}^{-1}\right)$, fasting c-peptide negative, treated with multiple daily insulin injections, no long-term complications and no other physical and/or mental diseases, which might influence the study results. In this primary investigation we recruited male individuals as the female menstrual cycle may influence the energy supply during CPX testing (23). Participants were excluded if they had a history of any disease that might confound the results of the trial, use of drugs, which may interfere with the interpretation of the trial's results or known to be clinically 
relevant in interfering with insulin action, glucose utilization or recovery from hypoglycemia, current addiction to alcohol or any controlled substance abuse. Furthermore, participants were excluded if they had known or suspected allergy to trial products or related products, mental incapacity, unwillingness, language barriers precluding adequate understanding, and any condition that the study physician feels would interfere with the trial participation. Testing day exclusion criteria were: hypoglycemia $48 \mathrm{~h}$ prior to testing, illness on or before the testing day, low glucose levels immediately before testing $(\leq 4.4$ mmol. $1^{-1}$ ) or alcohol consumption $24 \mathrm{~h}$ before. All data were assessed and documented in a standardized Case Report Form. CON individuals were selected with respect to T1D individuals' characteristics (matched for sex, age, and maximum power output) from routine diagnostics data at the entry to the physical education studies. CON individuals were instructed to avoid intense or long-lasting exercise $24 \mathrm{~h}$ prior to the investigation and to avoid alcohol within $24 \mathrm{~h}$ pre-testing. Written informed consent was obtained from all participants.

\section{Participants Characteristics}

T1D individuals' characteristics were: age $24 \pm 5$ years (minmax; 19-32), BMI $23.9 \pm 2.5 \mathrm{~kg} \cdot \mathrm{m}^{-2}$ (20-28), $\mathrm{HbA}_{1 \mathrm{c}} 7.4 \pm$ $0.6 \%(6.5-8)\left(57 \pm 6.3 \mathrm{mmol} . \mathrm{mol}^{-1}\right)$ (47-64), c-peptide $0.13 \pm$ $0.19 \mathrm{nmol}^{-1}(0-0.4)$ and total daily insulin dose with insulin Degludec $41 \pm 16 \mathrm{U}$ (27-69). Four participants used bolus insulin Aspart (Novo Rapid, Novo Nordisk, Denmark) and three participants used bolus insulin Lispro (Humalog/ Lilly, USA). Before switching to insulin Degludec, two patients used insulin Detemir (Levemir/ Novo Nordisk, Denmark) and five patients used insulin Glargine (Lantus/ Sanofi- Aventis, France) as basal therapy. T1D participants were free of comorbidities and comedications other than insulin. CON individuals were aged 23 \pm 4 years (19-30), had a BMI of $23.4 \pm 1.8 \mathrm{~kg} \cdot \mathrm{m}^{2}(21-26)$ and were healthy without taking any medications.

\section{Study Procedures}

In this experimental design, T1D individuals were adjusted to the same therapy with insulin Degludec $\left({ }^{\circledR}\right.$ Tresiba/Novo Nordisk, Dagsvaerd, Denmark) as part of a basal-bolus routine. After a run-in period of 4 weeks with insulin Degludec, a CPX test was performed. Insulin Degludec was used to achieve homogeneity for the basal insulin therapy. We have chosen insulin Degludec since its pharmacodynamic profile is flat and stable, demonstrated by an even distribution of glucose-lowering effects across the 24-h period (24).

\section{Cardio-Pulmonary Exercise (CPX) Testing}

Fourteen participants performed a maximum CPX test on a cycle ergometer (Monark Ergomedic 839E, Monark, Sweden) at the Sports Science Institute, University of Graz, Austria (25). Participants were permitted to cycle at a cadence of 70-90 $\mathrm{rpm}$. At the beginning of the CPX testing, participants sat on the cycle ergometer for $3 \mathrm{~min}$ without pedaling $(0 \mathrm{~W})$. Then, participants started to cycle for 3 min with a workload of $40 \mathrm{~W}$. Subsequently, the workload was increased by $20 \mathrm{~W}$ every minute until volitional exhaustion, followed by $3 \mathrm{~min}$ of active recovery at $40 \mathrm{~W}$ and $3 \mathrm{~min}$ of passive recovery $(0 \mathrm{~W}) . \mathrm{LTP}_{1}$ and $\mathrm{LTP}_{2}$ (12) as well as $\mathrm{VT}_{1}$ and $\mathrm{VT}_{2}$ were determined from the CPX test by means of a computer-based linear regression break point analysis (6). $\mathrm{LTP}_{1}$ was defined as the first increase in capillary blood lactate concentration above baseline values and $\mathrm{LTP}_{2}$ was defined as the second abrupt increase between $\mathrm{LTP}_{1}$ and the maximum power output. $\mathrm{VT}_{1}$ was defined as the first increase in ventilation (VE) accompanied by an increase in $\mathrm{VE} / \mathrm{VO}_{2}$ without an increase in $\mathrm{VE} / \mathrm{VCO}_{2} . \mathrm{VT}_{2}$ was defined as the second abrupt increase in $\mathrm{VE}$ accompanied by an increase in both $\mathrm{VE} / \mathrm{VO}_{2}$ and $\mathrm{VE} / \mathrm{VCO}_{2}$. Additionally, the heart rate turn point was defined as the point of intersection of two regression lines in the heart rate to performance curve between $\mathrm{LTP}_{1}$ and the maximum power output with minimal standard deviation of the two straight lines. The degree and direction of the deflection of the heart rate to performance curve $\left(\mathrm{k}_{\mathrm{HR}}\right)$ was calculated by a second-degree polynomial function between $\mathrm{LTP}_{1}$ and the maximum power output $(12,21)$.

\section{MEASUREMENTS}

Pulmonary gas-exchange variables were measured continuously during CPX testing via breath-by-breath measurement and $5 \mathrm{~s}$ average (ZAN 600, ZAN, Germany). Heart rate was measured continuously via chest belt telemetry and $5 \mathrm{~s}$ average (PE 4000, Polar Electro, Finland). A 12-lead electrocardiogram and blood pressure measurements (every $2 \mathrm{~min}$ ) were obtained during CPX testing for cardiac monitoring. Blood lactate and blood glucose (for safety in T1D group) concentrations were determined by taking capillary blood samples from the earlobe at the end of the rest and warm-up periods, at the end of each workload step (every minute), and at the end of active and passive recovery. Blood lactate and blood glucose were analyzed by means of an enzymatic-amperometric method $\left({ }^{\circledR}\right.$ Biosen S-line, EKF Diagnostics, Germany).

\section{Bolus Insulin Dose Reduction}

After overnight fasting, T1D individuals received a standardized meal on the day of the CPX test $\left({ }^{\circledR}\right.$ Fortimel Extra, Nutricia $\mathrm{GmbH}$, Germany), which was calculated from the average preinvestigational amount of consumed carbohydrates during the last 4 weeks prior to the start of the study. The standardized meal and the reduced bolus insulin dose were administered exactly $4 \mathrm{~h}$ before the cycle ergometer exercise tests. The bolus insulin dose was reduced by $40 \%$ of the regular dose for the CPX testing. Both groups were informed to ingest carbohydrate enriched meals at least the day prior CPX testing to ensure adequate tissue glycogen stores.

\section{Statistical Analyses}

All data were tested with Shapiro-Wilk normality test and were found to be normally distributed. Descriptive statistics included mean and standard deviation for participant's anthropometric data, performance characteristics, and diabetes specific data. Anthropometric data and $\mathrm{k}_{\mathrm{HR}}$ were compared between groups by paired students' $t$-test. Differences in comparison of groups for thresholds $\mathrm{LTP}_{1}, \mathrm{VT}_{1}, \mathrm{LTP}_{2}, \mathrm{VT}_{2}$, and heart rate turn 
point for relative and absolute power output, heart rate, oxygen consumption and lactate concentration were analyzed by a twoway ANOVA (group and threshold), with Bonferroni post-hoc testing. All statistics were performed with a standard software package ${ }^{\circledR}$ Prism Software version 5.0 (GraphPad, USA) and SPSS 22.0 software (SPSS Inc., USA).

\section{RESULTS}

Post-hoc power analysis was performed for the primary outcome percentages of heart rate comparing markers of lowest significant difference between groups $\left(\mathrm{VT}_{1}\right)$ and revealed a post hoc power $1-\beta=0.99$. There were no episodes of hypoglycemia noted during the CPX testing in the T1D group. T1D individuals maintained a blood glucose steady state during CPX testing showing no significant difference between the start $(10.58 \pm 3.42$ mmol. $\left.\mathrm{l}^{-1}\right)$ and the end concentrations $\left(10.24 \pm 3.48 \mathrm{mmol.} \mathrm{l}^{-1}\right)$ $(p=0.86)$.

Cardio-respiratory and metabolic markers at $\mathrm{LTP}_{1}$ and $\mathrm{VT}_{1}$ [T1D: $p=0.98$ (heart rate), $p=0.99$ (oxygen uptake), $p=0.92$ (lactate concentration); $\mathrm{CON}: p=0.96$ (heart rate), $p=0.60$ (oxygen uptake), $p=0.96$ (lactate concentration)] as well as $\mathrm{LTP}_{2}, \mathrm{VT}_{2}$ and heart rate turn point [T1D: $p=0.93$ (heart rate), $p=0.99$ (oxygen uptake), $p=0.58$ (lactate concentration); CON: $p=0.37$ (heart rate), $p=0.97$ (oxygen uptake), $p=0.76$ (lactate concentration)] were not significantly different within both groups.

No significant differences were found for power output, heart rate, oxygen uptake and lactate concentration at $\mathrm{LTP}_{1}, \mathrm{LTP}_{2}$, heart rate turn point, and maximum power output between T1D and CON individuals, except for lactate concentration at $\mathrm{LTP}_{1}$ (Table 1).

Significantly lower values were found for heart rate at percentages of maximum heart rate at $\mathrm{LTP}_{1}, \mathrm{VT}_{1}, \mathrm{LTP}_{2}$, $\mathrm{VT}_{2}$, and heart rate turn point as well as for heart rate at percentages of heart rate reserve at $\mathrm{LTP}_{2}, \mathrm{VT}_{2}$, and heart rate turn point in T1D individuals $(p<0.05)$. No significant differences were found for the oxygen uptake at percentages of maximum oxygen uptake $(p=0.88)$, oxygen uptake at percentages of oxygen uptake reserve $(p=0.71)$ and heart rate at percentages of heart rate reserve (only for $\mathrm{LTP}_{1}$ and $\left.\mathrm{VT}_{1}, p=0.11\right)$ as well as percentages of maximum power output $\% \mathrm{P}(p=0.64)$ at $\mathrm{LTP}_{1}, \mathrm{VT}_{1}, \mathrm{LTP}_{2}, \mathrm{VT}_{2}$, and heart rate turn point when comparing $\mathrm{T} 1 \mathrm{D}$ and $\mathrm{CON}$ individuals (Figure 1).

$\mathrm{k}_{\mathrm{HR}}$ was significantly lower in T1D individuals compared to CON individuals $(0.11 \pm 0.25$ vs. $0.51 \pm 0.32, p=0.02)$. Figure 2 shows the time course of the heart rate to performance curve for both groups indicating the differences especially important for the upper limit for vigorous intensity exercise. Usually, maximum heart rate derived calculations of the target training heart rate overestimate the true limits, as this can be seen via lactate turn points (Figure 2). The usual upper limit of $85 \%$ of the maximum heart rate was clearly above the exercise intensity of $\mathrm{LTP}_{2}$ for T1D individuals and clearly below $\mathrm{LTP}_{2}$ for $\mathrm{CON}$ individuals. Eighty-five percent of the
TABLE 1 | Comparison of anthropometric data, performance data and physiological data during CPX testing.

\begin{tabular}{|c|c|c|c|}
\hline & T1D $(n=7)$ & $\operatorname{coN}(n=7)$ & $p$-value \\
\hline Age (years) & $24.5 \pm 5.3$ & $23.4 \pm 4.1$ & 0.47 \\
\hline $\mathrm{BMI}\left(\mathrm{kg} / \mathrm{m}^{2}\right)$ & $23.9 \pm 2.5$ & $23.4 \pm 1.8$ & 0.70 \\
\hline $\mathrm{HbA}_{1 \mathrm{c}}(\%)$ & $7.4 \pm 0.6$ & - & - \\
\hline $\mathrm{HbA}_{1 \mathrm{c}}\left(\mathrm{mmol} . \mathrm{mol}^{-1}\right)$ & $57 \pm 6.3$ & - & - \\
\hline Diabetes duration (years) & $16.9 \pm 8.1$ & - & - \\
\hline PLtP1 (Watt) & $83 \pm 18$ & $92 \pm 22$ & 0.41 \\
\hline $\mathrm{P}_{\mathrm{VT} 1}$ (Watt) & $82 \pm 8$ & $103 \pm 12$ & 0.17 \\
\hline PLTP2 (Watt) & $192 \pm 33$ & $197 \pm 30$ & 0.74 \\
\hline$P_{\text {VT2 }}$ (Watt) & $193 \pm 14$ & $198 \pm 15$ & 0.80 \\
\hline$P_{\text {HRTP }}$ (Watt) & $198 \pm 40$ & $197 \pm 30$ & 0.93 \\
\hline$P_{\max }($ Watt $)$ & $284 \pm 43$ & $296 \pm 37$ & 0.58 \\
\hline $\mathrm{HR}_{\mathrm{LTP} 1}\left(\mathrm{~b} \cdot \mathrm{min}^{-1}\right)$ & $116 \pm 14$ & $127 \pm 12$ & 0.13 \\
\hline $\mathrm{HR}_{\mathrm{VT} 1}\left(\mathrm{~b} \cdot \mathrm{min}^{-1}\right)$ & $116 \pm 5$ & $128 \pm 5$ & 0.14 \\
\hline $\mathrm{HR}_{\mathrm{LTP} 2}\left(\mathrm{~b} \cdot \mathrm{min}^{-1}\right)$ & $159 \pm 11$ & $165 \pm 10$ & 0.28 \\
\hline $\mathrm{HR}_{\mathrm{VT} 2}\left(\mathrm{~b} \cdot \mathrm{min}^{-1}\right)$ & $159 \pm 4$ & $166 \pm 5$ & 0.17 \\
\hline $\mathrm{HR}_{\text {HRTP }}\left(\mathrm{b} \cdot \mathrm{min}^{-1}\right)$ & $160 \pm 10$ & $165 \pm 10$ & 0.38 \\
\hline $\mathrm{HR}_{\max }\left(\mathrm{b} \cdot \min ^{-1}\right)$ & $192 \pm 4$ & $187 \pm 11$ & 0.30 \\
\hline $\mathrm{VO}_{2 \mathrm{LTP} 1}\left(\mathrm{ml} \cdot \mathrm{kg}^{-1} \cdot \mathrm{min}^{-1}\right)$ & $19.88 \pm 14$ & $20.53 \pm 2.73$ & 0.80 \\
\hline $\mathrm{VO}_{2 \mathrm{VT} 1}\left(\mathrm{ml} \cdot \mathrm{kg}^{-1} \cdot \mathrm{min}^{-1}\right)$ & $19.89 \pm 2.75$ & $19.73 \pm 1.11$ & 0.95 \\
\hline $\mathrm{VO}_{2 \mathrm{LTP} 2}\left(\mathrm{ml} \cdot \mathrm{kg}^{-1} \cdot \mathrm{min}^{-1}\right)$ & $38.20 \pm 9.05$ & $38.26 \pm 4.21$ & 0.98 \\
\hline $\mathrm{VO}_{2 \mathrm{VT} 2}\left(\mathrm{ml} \cdot \mathrm{kg}^{-1} \cdot \mathrm{min}^{-1}\right)$ & $38.67 \pm 3.50$ & $38.07 \pm 2.02$ & 0.88 \\
\hline $\mathrm{VO}_{2 \mathrm{HRTP}}\left(\mathrm{ml} \cdot \mathrm{kg}^{-1} \cdot \mathrm{min}^{-1}\right)$ & $39.82 \pm 10.93$ & $38.61 \pm 4.58$ & 0.79 \\
\hline $\mathrm{VO}_{2 \max }\left(\mathrm{ml} \cdot \mathrm{kg}^{-1} \cdot \mathrm{min}^{-1}\right)$ & $52.49 \pm 6.56$ & $52.39 \pm 8.57$ & 0.98 \\
\hline LALTP1 $\left(m m o l . I^{-1}\right)$ & $0.91 \pm 0.24$ & $1.50 \pm 0.58$ & $0.03^{\star}$ \\
\hline $\mathrm{LA}_{\mathrm{VT} 1}\left(\mathrm{mmol} . \mathrm{I}^{-1}\right)$ & $0.90 \pm 0.11$ & $1.48 \pm 0.24$ & 0.05 \\
\hline LA LTP2 $\left(m m o l . I^{-1}\right)$ & $3.68 \pm 0.53$ & $4.10 \pm 0.50$ & 0.16 \\
\hline LA & $3.75 \pm 0.23$ & $4.18 \pm 0.21$ & 0.20 \\
\hline LA HRTP (mmol. $\left.I^{-1}\right)$ & $3.98 \pm 0.49$ & $3.88 \pm 1.12$ & 0.83 \\
\hline $\mathrm{LA}_{\max }\left(\mathrm{mmol} . \mathrm{I}^{-1}\right)$ & $12.37 \pm 1.25$ & $13.10 \pm 0.79$ & 0.21 \\
\hline
\end{tabular}

T1D: individuals with type 1 diabetes, CON: healthy individuals, LTP1, first lactate turn point; LTP2, second lactate turn point; HRTP, heart rate turn point; max, maximum output; $P$, power output; HR, heart rate; VO2, oxygen uptake; LA, lactate concentration; Values are given as mean $\pm S D$. * represents significant difference.

maximum heart rate resulted in significant differences comparing T1D vs. CON for oxygen uptake at percentages of maximum oxygen uptake [mean difference (MD) 11.57, confidence interval (CI) 0.15 to $22.99 \%, p=0.04$ ], oxygen uptake at percentages of oxygen uptake reserve $(12.86,1.43$ to $24.28, p=0.02)$, and power output at percentages of maximum power output (12.57, 1.15 to $23.99 \%, p=0.02)$, but not for heart rate at percentages of heart rate reserve $(3.71,-7.70$ to $15.13 \%$, $p=0.87)$.

\section{DISCUSSION}

The aim of this study was to investigate the alterations in the heart rate during CPX testing in T1D individuals compared to matched $\mathrm{CON}$ individuals. $\mathrm{k}_{\mathrm{HR}}$ was significantly different between T1D individuals and CON individuals. T1D individuals showed a lower heart rate of percentages of the maximum 


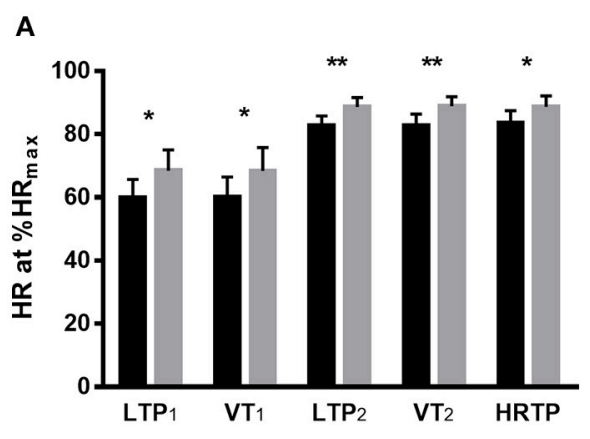

C

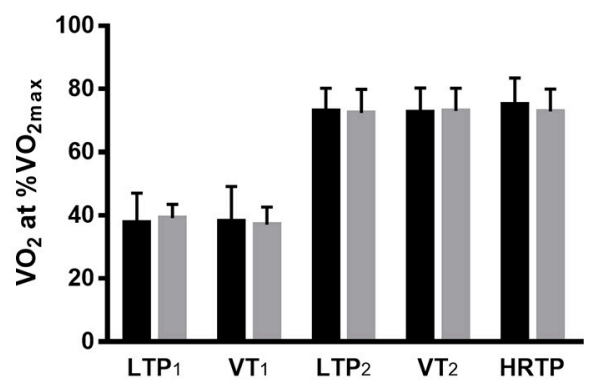

E

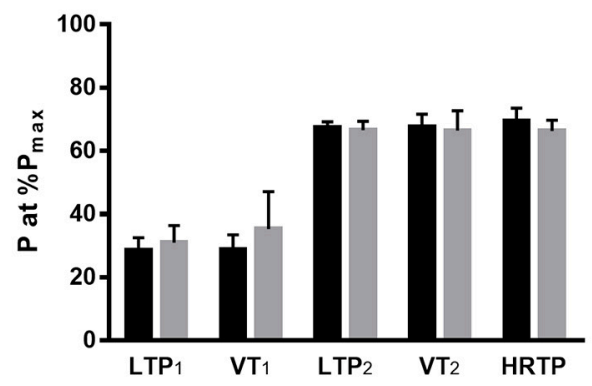

B

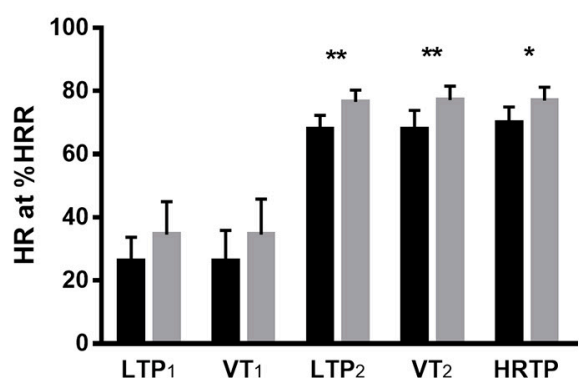

D

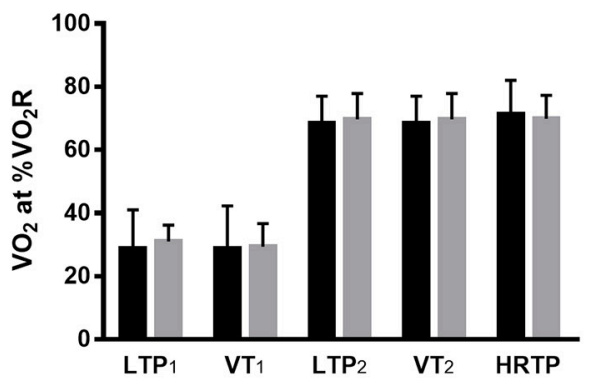

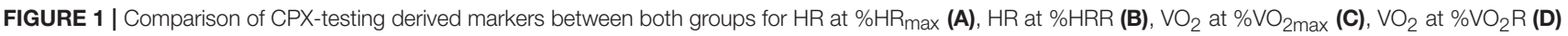
and $\mathrm{P}$ at $\% \mathrm{P}_{\max }(\mathbf{E})$. \%HRmax, percentage of maximum heart rate; \%HRR, percentage of heart rate reserve; \%VO $\mathrm{H}_{2 \mathrm{max}}$, percentage of maximum oxygen uptake; $\% \mathrm{VO}_{2} \mathrm{R}$, percentage of oxygen uptake reserve; \% $\mathrm{P}_{\max }$, percentage of maximum power output; LTP 1 , first lactate turn point; LTP 2 , second lactate turn point; HRTP, heart rate turn point; $\mathrm{VT}_{1}$, first ventilatory threshold; $\mathrm{VT}_{2}$, second ventilatory threshold. Values are given as mean $\pm \mathrm{SD}$. Stars represent significant difference, ${ }^{\star} p<0.05,{ }^{* *} p<0.01$. Black bar, individuals with type 1 diabetes; grey bar, healthy individuals.

heart rate at the second turn points $\left(\mathrm{LTP}_{2}, \mathrm{VT}_{2}\right.$, heart rate turn point) and a significantly lower $\mathrm{k}_{\mathrm{HR}}$ (Figure 2), which significantly influenced prescription of the target heart rate. Applying percentages of maximum heart rate derived markers overestimated T1D individuals' target training heart rate which is important especially for the upper limits for vigorous intensity exercise. All threshold values within groups were not significantly different ( $\mathrm{LTP}_{1}$ vs. $\mathrm{VT}_{1} ; \mathrm{LTP}_{2}$ vs. $\mathrm{VT}_{2}$ vs. heart rate turn point) indicating the objectivity and the validity of these markers which may be used interchangeably.

Different methods to prescribe exercise intensity for physical training show different advantages and disadvantages. As shown by our data, using percentages of maximum values [e.g., maximum heart rate or oxygen uptake (6)] is not sufficient to prescribe exercise intensity individually and might be impaired in patients with cardio-respiratory diseases. Submaximal threshold concepts (e.g., lactate-, ventilatory- and heart rate-derived) are a valid approach due to their theoretical foundation and its internal consistency. However, it must be stated that especially raterdepending software programs might be influenced by subjectivity that can alter exercise intensity prescription. Although oxygen uptake at percentages of maximum oxygen uptake, oxygen uptake at percentages of oxygen uptake reserve and heart rate at percentages of heart rate reserve (only for $\mathrm{LTP}_{1}$ and $\mathrm{VT}_{1}$ ) were not significantly different at all submaximal markers, heart rate at percentages of maximum heart rate at $\mathrm{LTP}_{1}, \mathrm{VT}_{1}$ and $\mathrm{LTP}_{2}, \mathrm{VT}_{2}$ and heart rate turn point as well as percentages of heart rate reserve at $\mathrm{LTP}_{2}, \mathrm{VT}_{2}$ and heart rate turn point were significantly lower in T1D individuals compared to CON individuals. It was previously shown that these differences were 


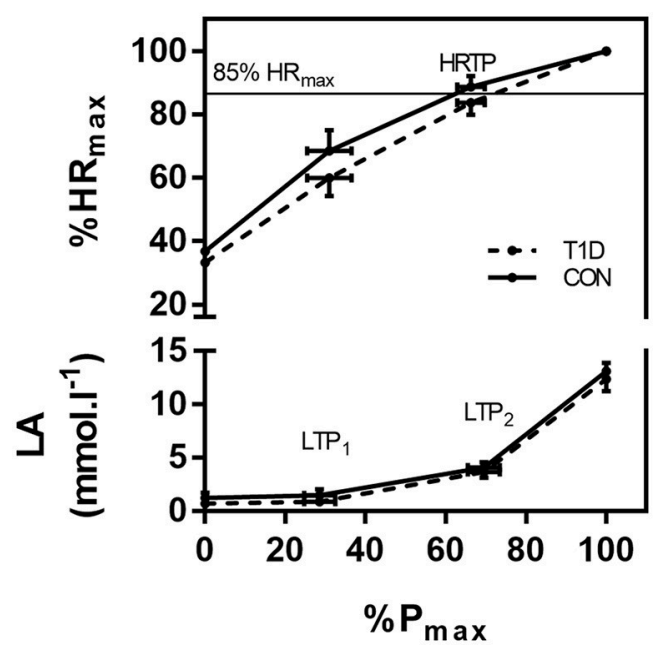

FIGURE 2 | Comparison of the relative heart rate performance curves and lactate curves between both groups. The same relative intensity of 85\% $\mathrm{HR}_{\text {max }}$, which is a usual upper limit for moderate intensity, resulted in different workloads related to the $\mathrm{LTP}_{2}$. \%HRmax, percentage of maximum heart rate; $\mathrm{LA}$, lactate concentration; \% $\mathrm{P}_{\max }$, percentage of maximum power output; $\mathrm{LTP}_{1}$, first lactate turn point; LTP 2 , second lactate turn point; HRTP, heart rate turn point. Values are given as mean $\pm S D$.

also found in young healthy and trained subjects (26) with about $15 \%$ of non-regular heart rate curves. However, in our study $62.5 \%$ of T1D individuals showed an atypical heart rate response.

In several studies, it was shown that $\mathrm{k}_{\mathrm{HR}}$ was associated with left ventricular ejection fraction $(12,16,27)$ and $\beta_{1}$ adrenoceptor sensitivity (28). In particular chronically elevated $\mathrm{HbA}_{1 \mathrm{c}}$ levels and concomitantly elevated catecholamine levels (29) or inflammation (30) may impair $\beta_{1}$-adrenoreceptor sensitivity. This might change the degree and direction of the deflection of the heart rate to performance curve as shown earlier by Wonisch et al. (10). Apart from the effects of chronic hyperglycemia, hypoglycemic episodes might further promote impaired cardiovascular function (31). T1D individuals experience on average two episodes of symptomatic hypoglycemia per week and at least one severe episode per year (32). Additionally, the incidence of severe hypoglycemia increases drastically with length of diabetes. Both hyperglycemia and recurrent hypoglycemia might be perpetrators for an impaired cardiac response during CPX testing in individuals with T1D. Overall, our data show a systematic overestimation of target heart rate in T1D individuals when applying percentages of maximum heart rate compared to objective individual markers of submaximal performance such as $\mathrm{LTP}_{1}, \mathrm{VT}_{1}, \mathrm{LTP}_{2}, \mathrm{VT}_{2}$, and heart rate turn point.

With respect to the findings in our study we consequently recommend using percentages of submaximal markers [e.g., the first and the second turn points for lactate $\left(\mathrm{LTP}_{1}\right.$ and $\left.\mathrm{LTP}_{2}\right)$ or ventilatory variables $\left.\left(\mathrm{VT}_{1}, \mathrm{VT}_{2}\right)\right]$ for the exercise intensity prescription in T1D which were shown to be representative for constant and intermittent type exercise of various intensities $(6,20,25)$. As shown in Figure 2, individuals with T1D might be exercising at a too high exercise intensity if exercise is prescribed by percentages of maximum heart rate. From a clinical point of view exercise intensity should be prescribed exactly to avoid both, unexpected hypoglycemia and to induce training effects. Since insulin needs to be reduced with light to moderate exercise intensity to avoid peri-exercise hypoglycemia, glucose levels remain relatively stable during exercise with vigorous intensity (33) and rise immediately after intense exercise is performed (34). If exercise intensity and the insulin dose reduction do not match accordingly, the risk of glycemic impairments rises (35) which could lead to severe health complications, including death (36). On the other hand, if the exercise intensity is close or below the $\mathrm{LTP}_{1}$, sub-optimal training effects on cardio-respiratory fitness may be expected, which reduces the possibility of attaining the accompanied health benefits.

To the best of our knowledge, this is the first study investigating the differences in cardio-pulmonary responses of the heart rate, heart rate reserve, oxygen uptake, and oxygen uptake reserve as well as maximum power output in relation to objective submaximal markers $\mathrm{LTP}_{1}, \mathrm{VT}_{1}, \mathrm{LTP}_{2}, \mathrm{VT}_{2}$, and heart rate turn point during CPX testing in T1D individuals and age, gender- and maximum power output- matched CON individuals. This study is limited by the small number of participants and that only males were included, which makes a direct transfer of the results to the general population of individuals with T1D difficult. Additionally, CON individuals were not provided with the same meal prior to the CPX testing as the T1D individuals. Further large-scale studies are needed investigating the heart rate to performance curve, which is obviously altered in this population. However, post-hoc power analysis confirmed the relevance of this study (power $1-\beta=0.99$ ).

In conclusion, our findings demonstrate that there are clear differences in heart rate responses during CPX testing in individuals with T1D compared to CON individuals. We postulate that $\mathrm{T} 1 \mathrm{D}$ individuals displayed an altered $\mathrm{k}_{\mathrm{HR}}$ and lowered percentages of maximum heart rate / percentages of heart rate reserve at submaximal markers. We recommend additional studies to analyze e.g., $\mathrm{HbA}_{1 \mathrm{c}}$ levels in relation to the heart rate to performance curve in a larger group of individuals with T1D.

\section{CONSENT OF PUBLICATION}

Both groups gave written signed informed consent for publication.

\section{AVAILABILITY OF DATA AND MATERIAL}

Data will be made available on demand by the corresponding authors via email contact.

\section{AUTHOR CONTRIBUTIONS}

All authors confirm that they meet the International Committee of Medical Journal Editors (ICMJE) uniform requirements for authorship. OM participated in the 
conceiving and designing the study, analyzing the data, and writing the manuscript. GT, AM, WG, and GK conceived the study and conducted the measurements. ME and $\mathrm{RB}$ conceived the study, analyzed data, drafted and revised the manuscript. $\mathrm{TP}$ and $\mathrm{PH}$ designed the study, supervised the measurements, and writing process. All authors

\section{REFERENCES}

1. Foulds HJA, Bredin SSD, Charlesworth SA, Ivey AC, Warburton DER. Exercise volume and intensity: a dose-response relationship with health benefits. Eur J Appl Physiol. (2014) 114:1563-71. doi: 10.1007/s00421-014-2887-9

2. Kodama S, Tanaka S, Heianza Y, Fujihara K, Horikawa C, Shimano H, et al. Association between physical activity and risk of all-cause mortality and cardiovascular disease in patients with diabetes: a meta-analysis. Diabetes Care (2013) 36:471-9. doi: 10.2337/dc12-0783

3. Colberg SR, Sigal RJ, Yardley JE, Riddell MC, Dunstan DW, Dempsey PC, et al. Physical activity/exercise and diabetes: a position statement of the American Diabetes Association. Diabetes Care (2016) 39:2065-79. doi: $10.2337 / \mathrm{dc} 16-1728$

4. Garber CE, Blissmer B, Deschenes MR, Franklin BA, Lamonte MJ, Lee IM, et al. Quantity and quality of exercise for developing and maintaining cardiorespiratory, musculoskeletal, and neuromotor fitness in apparently healthy adults: guidance for prescribing exercise. Med Sci Sports Exerc. (2011) 43:1334-59. doi: 10.1249/MSS.0b013e318213fefb

5. Chiang JL, Kirkman MS, Laffel LMB, Peters AL. Type 1 diabetes through the life span: a position statement of the American Diabetes Association. Diabetes Care (2014) 37:2034-54. doi: 10.2337/dc14-1140

6. Hofmann $P$, Tschakert G. Special needs to prescribe exercise intensity for scientific studies. Cardiol Res Pract. (2011) 2011:1-10. doi: $10.4061 / 2011 / 209302$

7. Scharhag-Rosenberger F, Meyer T, Gäßler N, Faude O, Kindermann W. Exercise at given percentages of VO2max: Heterogeneous metabolic responses between individuals. J Sci Med Sport (2010) 13:74-9. doi: 10.1016/j.jsams.2008.12.626

8. Aragão F, Moreira MH, Gabriel RE, Abrantes CG. The upper limit of the cardiorespiratory training zone $(40-84 \% \mathrm{HRR})$ is overestimated for postmenopausal women. J Sci Med Sport (2013) 16:571-6. doi: 10.1016/j.jsams.2012.12.008

9. Wolpern AE, Burgos DJ, Janot JM, Dalleck LC. Is a threshold-based model a superior method to the relative percent concept for establishing individual exercise intensity? a randomized controlled trial. BMC Sports Sci Med Rehabil. (2015) 7:16. doi: 10.1186/s13102-015-0011-z

10. Wonisch M, Hofmann P, Fruhwald FM, Kraxner W, Hodl R, Pokan R, et al. Influence of beta-blocker use on percentage of target heart rate exercise prescription. Eur J Cardiovasc Prev Rehabil. (2003) 10:296-301. doi: 10.1097/01.hjr.0000085249.65733.e2

11. Hofmann P, Von Duvillard SP, Seibert FJ, Pokan R, Wonisch M, Lemura LM, et al. \%HRmax target heart rate is dependent on heart rate performance curve deflection. Med Sci Sports Exerc. (2001) 33:1726-1731. doi: 10.1097/00005768-200110000-00017

12. Hofmann P, Pokan R, Duvillard S, Seibert F, Zweiker R, Schmid P. Heart rate performance curve during incremental cycle ergometer exercise in healthy young male subjects. Med Sci Sport Exerc. (1997) 762-8.

13. Dafaalla MD, Nimir MN, Mohammed MI, Ali OA, Hussein A. Risk factors of diabetic cardiac autonomic neuropathy in patients with type 1 diabetes mellitus: a meta-analysis. Open Hear (2016) 3:e000336. doi: 10.1136/openhrt-2015-000336

14. Mogensen UM, Jensen T, Køber L, Kelbæk H, Mathiesen AS, Dixen U, et al. Cardiovascular autonomic neuropathy and subclinical cardiovascular disease in normoalbuminuric type 1 diabetic patients. Diabetes (2012) 61:1822-30. doi: $10.2337 / \mathrm{db} 11-1235$

15. Pokan R, Hofmann P, Preidler K, Leitner H, Dusleag J, Eber B, et al. Correlation between inflection of heart rate/work performance curve and have approved the final version of the manuscript to be published.

\section{ACKNOWLEDGMENTS}

The authors want to thank the participants for their compliance. myocardial function in exhausting cycle ergometer exercise. Eur J Appl Physiol Occup Physiol. (1993) 67:385-8.

16. Hofmann P, Pokan R, Preidler K, Leitner H, Szolar D, Eber B, et al. Relationship between heart rate threshold, lactate turn point and myocardial function. Int J Sports Med. (1994) 15:232-7. doi: 10.1055/s-2007-1021052

17. Keytsman C, Dendale P, Hansen D. Chronotropic incompetence during exercise in type 2 diabetes: aetiology, assessment methodology, prognostic impact and therapy. Sport Med. (2015) 45:985-95. doi: $10.1007 / \mathrm{s} 40279-015-0328-5$

18. Brock C, Jessen N, Brock B, Jakobsen PE, Hansen TK, Rantanen JM, et al. Cardiac vagal tone, a non-invasive measure of parasympathetic tone, is a clinically relevant tool in Type 1 diabetes mellitus. Diabet Med (2017) 34:1428-34. doi: 10.1111/dme.13421

19. Tschakert G, Kroepfl J, Mueller A, Moser O, Groeschl W, Hofmann P. How to regulate the acute physiological response to "aerobic" high-intensity interval exercise. J Sport Sci Med. (2014) 14:29-36.

20. Moser O, Tschakert G, Mueller A, Groeschl W, Hofmann P, Pieber T, et al. Short-acting insulin reduction strategies for continuous cycle ergometer exercises in patients with type 1 diabetes mellitus. Asian J Sports Med. (2017) 8:e42160. doi: 10.5812/asjsm. 42160

21. Moser O, Eckstein ML, McCarthy O, Deere R, Bain SC, Haahr HL, et al. Heart rate dynamics during cardio-pulmonary exercise testing are associated with glycemic control in individuals with type 1 diabetes. PLOS ONE (2018) 13:e0194750. doi: 10.1371/journal.pone.0194750

22. Tschakert G, Hofmann P. High-intensity intermittent exercise: methodological and physiological aspects. Int J Sports Physiol Perform (2013) 8:600-610. doi: 10.1123/ijspp.8.6.600

23. Barata DS, Adan LF, Netto EM, Ramalho AC. The effect of the menstrual cycle on glucose control in women with type 1 diabetes evaluated using a continuous glucose monitoring system. Diabetes Care (2013) 36:e70. doi: $10.2337 / \mathrm{dc} 12-2248$

24. Haahr H, Heise T. A review of the pharmacological properties of insulin degludec and their clinical relevance. Clin Pharmacokinet (2014) 53:787-800. doi: 10.1007/s40262-014-0165-y

25. Moser O, Tschakert G, Mueller A, Groeschl W, Pieber TR, ObermayerPietsch B, et al. Effects of high-intensity interval exercise versus moderate continuous exercise on glucose homeostasis and hormone response in patients with type 1 diabetes mellitus using novel ultra-long-acting insulin. PLoS ONE (2015) 10:e0136489. doi: 10.1371/journal.pone.0136489

26. 2001-Hofmann-MedSciSportsExerc S1726-1731.pdf.

27. Pokan R, Hofmann P, Von Duvillard SP, Beaufort F, Schumacher M, Fruhwald FM, et al. Left ventricular function in response to the transition from aerobic to anaerobic metabolism. Med Sci Sports Exerc. (1997) 29:1040-7.

28. Hofmann P, Wonisch M, Pokan R, Schwaberger G, Smekal G, Von Duvillard SP. $\beta 1$-adrenoceptor mediated origin of the heart rate performance curve deflection. Med Sci Sports Exerc. (2005) 37:1704-9. doi: 10.1249/01.mss.0000176308.70316.cc

29. Heyman E, Delamarche P, Berthon P, Meeusen R, Briard D, Vincent S, et al. Alteration in sympathoadrenergic activity at rest and during intense exercise despite normal aerobic fitness in late pubertal adolescent girls with type 1 diabetes. Diabetes Metab. (2007) 33:422-9. doi: 10.1016/j.diabet.2007. 10.003

30. Euteneuer F, Mills PJ, Rief W, Ziegler MG, Dimsdale JE. Association of in vivo $\beta$-adrenergic receptor sensitivity with inflammatory markers in healthy subjects. Psychosom Med (2012) 74:271-7. doi: 10.1097/PSY.0b013e318245d762

31. Paty BW. The role of hypoglycemia in cardiovascular outcomes in diabetes. Can J Diabetes (2015) 39:S155-9. doi: 10.1016/j.jcjd.2015.09.009 
32. Cryer PE. Hypoglycemia in type 1 diabetes mellitus. Endocrinol Metab Clin North Am (2010) 39:641-54. doi: 10.1016/j.ecl.2010. 05.003

33. Campbell MD, West DJ, Bain SC, Kingsley MIC, Foley P, Kilduff L, et al. Simulated games activity vs continuous running exercise: A novel comparison of the glycemic and metabolic responses in T1DM patients. Scand J Med Sci Sports (2015) 25:216-22. doi: 10.1111/sms. 12192

34. Riddell MC, Gallen IW, Smart CE, Taplin CE, Adolfsson P, Lumb AN, et al. Exercise management in type 1 diabetes: a consensus statement. Lancet Diabetes Endocrinol. (2017) 8587:1-14. doi: 10.1016/S2213-8587(17) 30014-1

35. Rabasa-Lhoret R, Bourque J, Ducros F, Chiasson JL. Guidelines for premeal insulin dose reduction for postprandial exercise of different intensities and durations in type 1 diabetic subjects treated intensively with a basalbolus insulin regimen (ultralente-lispro). Diabetes Care (2001) 24:625-30. doi: $10.2337 /$ diacare.24.4.625

36. Tanenberg RJ, Newton CA, Drake AJ. Confirmation of hypoglycemia in the "dead-in-bed" syndrome, as captured by a retrospective continuous glucose monitoring system. Endocr Pract. (2010) 16:244-8. doi: 10.4158/ EP09260.CR
Conflict of Interest Statement: OM has received lecture fees from Medtronic, travel and research fees form Novo Nordisk A/S, Novo Nordisk Austria and Dexcom Inc. and received a grant from Ser Cymru II COFUND fellowship/European Union. ME has received a KESS2/European Social Fund scholarship. RB has received educational grants from Novo Nordisk, Eli Lilly, Sanofi, Boehringer Ingelheim, and Beneo. GK has received lecture fees and has participated in advisory panels from Novo Nordisk, Bohringer Ingelheim, Novartis, MSD, and Eli Lilly. TP has participated in advisory panels and acted as a consultant for Novo Nordisk.

The remaining authors declare that the research was conducted in the absence of any commercial or financial relationships that could be construed as a potential conflict of interest.

Copyright (c) 2018 Moser, Tschakert, Mueller, Groeschl, Eckstein, Koehler, Bracken, Pieber and Hofmann. This is an open-access article distributed under the terms of the Creative Commons Attribution License (CC BY). The use, distribution or reproduction in other forums is permitted, provided the original author $(s)$ and the copyright owner(s) are credited and that the original publication in this journal is cited, in accordance with accepted academic practice. No use, distribution or reproduction is permitted which does not comply with these terms. 